\title{
Determinants of the surface quality, density and dimensional correctness in selective laser melting of the $\mathrm{Ti}-13 \mathrm{Zr}-13 \mathrm{Nb}$ alloy
}

\author{
Tomasz Seramak ${ }^{1}$, Katarzyna Zasinska $^{2}$, Michel Mesnard ${ }^{3,}$, Karolina Bednarz ${ }^{1}$, Paulina Fic ${ }^{1}$, and Andrzej Zielinski ${ }^{1}$ \\ ${ }^{1}$ Gdansk University of Technology, Department of Materials Engineering and Bonding, 80-233 Gdansk, Poland \\ ${ }^{2}$ Gdansk University of Technology, Department of Machine Design and Motor Vehicles, 80-233 Gdansk, Poland \\ ${ }^{3}$ Université de Bordeaux, Institut de Mécanique et d'Ingénierie, CNRS UMR 5295, 33405 Talence, France
}

Received: 14 January 2018 / Accepted: 24 September 2018

\begin{abstract}
Selective laser melting is widely used for custom-designed elements. Successful manufacturing depends on laser treatment parameters and material features. This research aimed to determine the effects of laser power, scan time and hatch distance on surface quality, relative density and dimensional precision for cuboids made of the Ti-13Zr-13Nb alloy. The influence of energy density, energy flux and pre-heating was seen to be decisive to different degrees for the quality of the final specimen. The results obtained were used to produce prosthetic crowns and bridges. The thermal stresses that appeared resulted in a deflection of the bridges and consequently in a change in design approach.
\end{abstract}

Keywords: selective laser melting / titanium alloys / prosthetic elements / 3D printing quality

Résumé. Déterminants de la qualité de surface, de la densité et de l'exactitude dimensionnelle dans la fusion au laser (selective laser melting) de l'alliage Ti-13Zr-13Nb. La fusion par laser (selective laser melting) est largement utilisée pour produire des éléments personnalisés. La fabrication aboutie dépend des paramètres de traitement laser et des caractéristiques du matériau. Cette recherche visait à déterminer les effets de la puissance du laser, du temps de balayage et de la distance des balayages sur : la qualité de la surface, la densité relative et la précision dimensionnelle d'échantillons cubiques en alliage de titane Ti-13Zr-13Nb. L'influence de la densité d'énergie, du flux d'énergie et du préchauffage a été jugée déterminante à différents degrés pour la qualité de l'échantillon final. Les résultats obtenus ont été utilisés pour produire des couronnes dentaires et des ponts prothétiques. Les contraintes thermiques apparues ont entraîné une déviation des ponts et, par conséquent, une modification de la conception.

Mots clés: selective laser melting / alliages de titane / éléments prothétiques / qualité d'impression

\section{Introduction}

$3 \mathrm{D}$ printing of metallic parts is usually performed by additive manufacturing with the use of a laser beam and is known as selective laser melting (SLM)/selective laser sintering (SLS) [1]. Until now, a variety of elements, machine parts, and goods have been manufactured from titanium and its alloys, especially for medicine. The obtained so far alloys are shown in Table 1 [2-10].

The dental, joint and maxillofacial implants are made either by foundry or by CNC technique. The manufacturing of medical goods by SLM is the cheapest of the above techniques as some details may be obtained at the same

\footnotetext{
* e-mail: michel.mesnard@u-bordeaux.fr
}

time. The primary efforts are focused on the process optimization. The conventional machining route resulted in higher-dimensional accuracy and smooth surface finish of prostheses, and the rapid prototyping involved lesser time and cost, demonstrating rougher prosthesis surface and lower internal porosity [1]. The high accuracy of titanium and Co-Cr scaffolds may be obtained by SLM [12], but the process optimization needs considering the vast number of parameters. The zig-zag laser path strategy for SLM made Ti-6Al-4V robust specimens resulted in better accuracy, hardness and corrosion resistance within all planes [13]. When comparing three manufacturing methods for some dental Co-Cr details, conventional casting, laser sintering and $\mathrm{CAD} / \mathrm{CAM}$ milled technique, the significant differences in mechanical properties were observed, but all techniques were able to produce the 
Table 1. The Ti alloys manufactured by selective laser melting.

Tableau 1. Alliages de titane mis en forme par selective laser melting.

\begin{tabular}{ll}
\hline Alloy & Reference \\
\hline Ti-6Al-4V-Mo & 2 \\
Ti-24Nb-4Zr-8Zn (scaffold) & 3 \\
Ti-Re & 4 \\
Ti-5.5Al-3,4Sn-3.0Zr-0.7Mo- & 5 \\
0.3Si-0.4Nb-0.35Ta & \\
Ti-Nb & 6 \\
Ti-15Ta-xZr (1.5, 5.5, 10.5 or 15.5Zr) & 7 \\
Ti-15Mo-5Zr-3Al & 8 \\
Ti-5Al-2.5Sn & 9 \\
Ti-13Zr-13Nb & 10 \\
\hline
\end{tabular}

specimens satisfying the ISO standards for dental alloys [14]. The bone augmentation using pre-formed titanium mesh with bone graft and alloplastic material was made by 3D modeling and design, and manufacturing of models and pre-formed meshes by either fused deposition modeling (FDM) or direct metal laser sintering (DMLS) [15].

The SLM method was sometimes combined with other technologies to optimize the process. For the Ti-6Al-4V alloy, the selective laser melting (SLM) and 5-axis CNC milling were joined to produce aerospace parts from titanium powder with lower wastage [16]. The SLM was also combined with hot isostatic pressing (HIPS) to manufacture the Ti-6Al-4V alloy [17].

The heat treatments of SLM made parts were investigated to improve the mechanical properties. Such improvement was achieved for the Ti-6Al-4V alloy by the precision forging at $950{ }^{\circ} \mathrm{C}$ [18] and by recrystallization annealing [19].

In medicine, the dental implants, maxillofacial implants, and prosthetic parts were the most often produced by the SLM method. The SLM followed by laser gas nitriding was used to make the dental implants of increased wear resistance [20]. The titanium denture base plates were CAD/CAM designed, and rapid laser formed [21]. The customized brackets were made of 316 stainless steel by SLM, using $316 \mathrm{~L}$ stainless steel at process parameters optimized to achieve the best shape accuracy, dimensional precision and proper density of orthodontic goods [22]. The SLM was also applied [23] to fabricate thin titanium alloy frameworks for a complete maxillary denture.

In many reports, the process parameters appropriate for the necessary quality of SLM were looked for titanium and some of its alloys. For the laser sintering of titanium, the Nd:YAG laser of power in the range $10-100 \mathrm{~W}$ focused for $10 \mathrm{~s}$ on loose Ti powder of $63-315 \mu \mathrm{m}$ particle size [24]. For the Ti-6Al-4V alloy, the best accuracy was obtained at laser power $95 \mathrm{~W}$, layer thickness $30 \mu \mathrm{m}$, scan speed $125 \mathrm{~mm} / \mathrm{s}$, hatching space $130 \mu \mathrm{m}$ and energy density $195 \mathrm{~J} / \mathrm{mm}^{3}[25]$. The composite Ti-6Al-7Nb and hydroxyapatite were manufactured with a laser power of $50 \mathrm{~W}[26]$.
The texture and mechanical properties of SLM made titanium were dependent on laser power: at $50 \mathrm{~W}$ a strongtextured $\mathrm{Ti}$ with anisotropic mechanical properties and at $250 \mathrm{~W}$ a low-textured material with high strength was obtained [27].

So far, research has shown that the SLM manufacturing is suitable to produce various medical parts. Such goods are much cheaper than those made by other methods, but the accuracy of the obtained details is significantly shaped by some process parameters, individually established for any material and kind of part. This research aimed to determine the most critical process parameters and their optimal values for manufacturing the prosthetic foundations and bridges of the Ti-13Zr-13Nb alloy, nowadays the most appropriate medical titanium alloy for many applications.

\section{Materials and methods}

The Ti-13Zr-13Nb powder was obtained by electrode induction-melting gas atomization (TLS-Technik, Germany). The powder grain size ranged between 50 and $100 \mu \mathrm{m}$. Over $90 \%$ of grains were spheroidal in shape. The chemical composition was: $\mathrm{Zr} \mathrm{13.0,} \mathrm{Nb} \mathrm{13.0,} \mathrm{Fe} \mathrm{0.005,} \mathrm{C} \mathrm{0.004,}$ $\mathrm{N} 0.019$, O $0.011 \mathrm{wt} . \%$ and Ti the remainder.

The project was divided into two stages. In the first stage, using model specimens, cuboids of two dimensions, $5 \times 0.05 \times 5 \mathrm{~mm}$ and $5 \times 0.2 \times 5 \mathrm{~mm}$, were designed with the Autodesk Inventor Professional 2015 software. At the second stage, the foundations and prosthetic bridges were designed using similar CAD/CAM software based on real models obtained from scans of the mouth of some patients. Afterward, the stl. files were developed for the SLM process.

The specimens were manufactured by the Realizer SLM 100 equipment utilizing the ytterbium one mode fiber laser CW, series YLR-100-SM, at a wavelength of about $1070 \mathrm{~nm}$. At the first stage, the following parameters were used: power laser 80,90 and $100 \mathrm{~W}$, laser beam distance 30,40 and $50 \mu \mathrm{m}$, the exposure time for a single point 80,90 and $100 \mu \mathrm{s}$. The laser beam size was set at $100 \mu \mathrm{m}$ and the thickness of a single layer at $30 \mu \mathrm{m}$. Tests were carried out for all 27 combinations of the above parameters. At the second stage, based on these tests, selected laser treatment parameters were applied.

At the first stage, the surfaces of melted specimens were examined with the stereoscopic light microscope, and linear dimensions of the upper sides were measured to an accuracy of $0.01 \mathrm{~mm}$. Based on that, the visible surface quality was assessed by Quality Function Deployment. Eleven features were assessed, each in a 5-point range, from one (the worst) to five (the best), by a team of two assessors that pointed out:

- difference between the thickness of the melted specimen at the center and the thickness compared to the specification of the CAD model;

- difference between the average of two upper sides of the melted specimen and the dimension according to the CAD model; 
Table 2. Dimensions of model specimens at different laser treatment parameters.

Tableau 2. Dimensions des échantillons pour différents paramètres de traitement.

\begin{tabular}{|c|c|c|c|c|c|c|c|c|c|c|}
\hline \multirow[b]{3}{*}{ No. } & \multirow[b]{3}{*}{$\begin{array}{l}\text { Laser } \\
\text { power } \\
\text { [W] }\end{array}$} & \multirow[b]{3}{*}{$\begin{array}{l}\text { Scan } \\
\text { time } \\
{[\mu \mathrm{s}]} \\
\end{array}$} & \multirow[b]{3}{*}{$\begin{array}{l}\text { Hatch } \\
\text { distance } \\
{[\mu \mathrm{m}]}\end{array}$} & \multirow[b]{3}{*}{$\begin{array}{l}\text { Scan } \\
\text { rate } \\
{[\mathrm{m} / \mathrm{s}]} \\
\end{array}$} & \multirow[b]{3}{*}{$\begin{array}{c}\text { Energy } \\
\text { density } \\
{\left[\mathrm{J} / \mathrm{mm}^{2}\right]}\end{array}$} & \multicolumn{5}{|c|}{ Dimensions [mm] } \\
\hline & & & & & & \multicolumn{3}{|c|}{ Thickness [mm] } & \multicolumn{2}{|c|}{ Length $[\mathrm{mm}]$} \\
\hline & & & & & & Centre & Edge 1 & Edge 2 & Centre & $\begin{array}{l}\text { Upper } \\
\text { edge }\end{array}$ \\
\hline 1 & 100 & 80 & 30 & 0.38 & 2.67 & 0.32 & 0.34 & 0.34 & 5.22 & 5.23 \\
\hline 2 & 100 & 90 & 30 & 0.33 & 3.00 & 0.30 & 0.36 & 0.39 & 5.21 & 5.22 \\
\hline 3 & 100 & 100 & 30 & 0.30 & 3.33 & 0.34 & 0.43 & 0.42 & 5.14 & 5.22 \\
\hline 4 & 90 & 80 & 30 & 0.38 & 2.40 & 0.31 & 0.38 & 0.35 & 5.21 & 5.27 \\
\hline 5 & 90 & 90 & 30 & 0.33 & 2.70 & 0.30 & 0.38 & 0.35 & 5.21 & 5.23 \\
\hline 6 & 90 & 100 & 30 & 0.30 & 3.00 & 0.32 & 0.36 & 0.37 & 5.17 & 5.19 \\
\hline 7 & 80 & 80 & 30 & 0.38 & 2.13 & 0.34 & 0.43 & 0.43 & 5.20 & 5.24 \\
\hline 8 & 80 & 90 & 30 & 0.33 & 2.40 & 0.31 & 0.38 & 0.36 & 5.22 & 5.25 \\
\hline 9 & 80 & 100 & 30 & 0.30 & 2.67 & 0.35 & 0.37 & 0.36 & 5.13 & 5.18 \\
\hline 10 & 100 & 80 & 40 & 0.50 & 2.00 & 0.31 & 0.37 & 0.41 & 5.20 & 5.23 \\
\hline 11 & 100 & 90 & 40 & 0.44 & 2.25 & 0.32 & 0.39 & 0.42 & 5.20 & 5.26 \\
\hline 12 & 100 & 100 & 40 & 0.40 & 2.50 & 0.31 & 0.38 & 0.39 & 5.18 & 5.17 \\
\hline 13 & 90 & 80 & 40 & 0.50 & 1.80 & 0.25 & 0.35 & 0.37 & 5.25 & 5.26 \\
\hline 14 & 90 & 90 & 40 & 0.44 & 2.03 & 0.33 & 0.38 & 0.39 & 5.22 & 5.25 \\
\hline 15 & 90 & 100 & 40 & 0.40 & 2.25 & 0.34 & 0.40 & 0.36 & 5.15 & 5.20 \\
\hline 16 & 80 & 80 & 40 & 0.50 & 1.60 & 0.28 & 0.33 & 0.36 & 5.19 & 5.26 \\
\hline 17 & 80 & 90 & 40 & 0.44 & 1.80 & 0.29 & 0.38 & 0.39 & 5.21 & 5.26 \\
\hline 18 & 80 & 100 & 40 & 0.40 & 2.00 & 0.32 & 0.35 & 0.41 & 5.16 & 5.16 \\
\hline 19 & 100 & 80 & 50 & 0.63 & 1.60 & 0.24 & 0.34 & 0.36 & 5.24 & 5.26 \\
\hline 20 & 100 & 90 & 50 & 0.56 & 1.80 & 0.28 & 0.36 & 0.39 & 5.20 & 5.26 \\
\hline 21 & 100 & 100 & 50 & 0.50 & 2.00 & 0.24 & 0.29 & 0.26 & 5.14 & 5.15 \\
\hline 22 & 90 & 80 & 50 & 0.63 & 1.44 & 0.25 & 0.36 & 0.38 & 5.24 & 5.25 \\
\hline 23 & 90 & 90 & 50 & 0.56 & 1.62 & 0.24 & 0.32 & 0.29 & 5.20 & 5.23 \\
\hline 24 & 90 & 100 & 50 & 0.50 & 1.80 & 0.27 & 0.31 & 0.33 & 5.17 & 5.21 \\
\hline 25 & 80 & 80 & 50 & 0.63 & 1.28 & 0.29 & 0.34 & 0.35 & 5.23 & 5.23 \\
\hline 26 & 80 & 90 & 50 & 0.56 & 1.44 & 0.24 & 0.33 & 0.35 & 5.25 & 5.27 \\
\hline 27 & 80 & 100 & 50 & 0.50 & 1.60 & 0.24 & 0.27 & 0.32 & 5.17 & 5.19 \\
\hline
\end{tabular}

- straightness of melt based on an examination of the upper surface;

- bulges on the melted part based on an examination of the upper surface;

- average sample length - should be as close as possible to the CAD model dimensions. The differences between the length of the CAD model and mean of 10 measurements of sample length along its whole height were estimated;

- sample length measured along the specimen's upper edge (last layers of the printed sample);

- visibility of layers;

- unmelted powder particles on the surface;

- local agglomerates of melts;

- bold vertical edges;

- unevenness - to assess this, features 8, 9 and 10 were taken into account.
Afterward, the density of melted specimens was measured for the best six of twenty-seven combinations of parameters. This was based on tests carried out with micro computer tomography $(\mu \mathrm{CT})$ using the $\mathrm{v}$ |tome| xs 240 system from General Electric. Then two final combinations of parameters, of the highest density, qualitatively best surface and dimensions the closest to the CAD model, were investigated.

\section{Results}

The results of investigations of all combinations of three laser treatment parameters are shown in Table 2 . The results are not unequivocal. The QFD analysis (Tab. 3) demonstrates the influence of all parameters on the surface quality. 
Table 3. Results of QFD analysis at different laser treatment parameters.

Tableau 3. Résultats de l'analyse QFD pour différents paramètres de traitement.

\begin{tabular}{lllll}
\hline No. & $\begin{array}{l}\text { Laser } \\
\text { power }[\mathrm{W}]\end{array}$ & $\begin{array}{l}\text { Scan } \\
\text { time }[\mu \mathrm{s}]\end{array}$ & $\begin{array}{l}\text { Hatch } \\
\text { distance }[\mu \mathrm{m}]\end{array}$ & $\begin{array}{l}\text { QFD } \\
\text { value }\end{array}$ \\
\hline 1 & 100 & 80 & 30 & 37 \\
2 & 100 & 90 & 30 & 34 \\
3 & 100 & 100 & 30 & 36 \\
4 & 90 & 80 & 30 & 28 \\
5 & 90 & 90 & 30 & 28 \\
6 & 90 & 100 & 30 & 34 \\
7 & 80 & 80 & 30 & 25 \\
8 & 80 & 90 & 30 & 27 \\
9 & 80 & 100 & 30 & 34 \\
10 & 100 & 80 & 40 & 34 \\
11 & 100 & 90 & 40 & 33 \\
12 & 100 & 100 & 40 & 36 \\
13 & 90 & 80 & 40 & 30 \\
14 & 90 & 90 & 40 & 29 \\
15 & 90 & 100 & 40 & 32 \\
16 & 80 & 80 & 40 & 31 \\
17 & 80 & 90 & 40 & 30 \\
18 & 80 & 100 & 40 & 37 \\
19 & 100 & 80 & 50 & 32 \\
20 & 100 & 90 & 50 & 28 \\
21 & 100 & 100 & 50 & 43 \\
22 & 90 & 80 & 50 & 33 \\
23 & 90 & 90 & 50 & 39 \\
24 & 90 & 100 & 50 & 41 \\
25 & 80 & 80 & 50 & 31 \\
26 & 80 & 90 & 50 & 53 \\
27 & 80 & 100 & 50 & \\
\hline & & & & 50 \\
\hline
\end{tabular}

Table 4. Densities of selected model specimens expressed as the ratio of real density to theoretical density.

Tableau 4. Densité de spécimens exprimée sous la forme d'un rapport entre la densité réelle et la densité théorique.

\begin{tabular}{ll}
\hline No. & Relative density [\%] \\
\hline 3 & 96.92 \\
12 & 96.74 \\
15 & 97.95 \\
18 & 98.24 \\
21 & 97.62 \\
24 & 97.67 \\
\hline
\end{tabular}

For six selected combinations, the density of model specimens examined with the $\mu \mathrm{CT}$ is shown in Table 4 . Pore size ranged between $3.5 \times 10^{-6}$ and $5 \times 10^{-6} \mathrm{~mm}^{3}$.
Figures 1 and 2 demonstrate the differences between real and CAD model dimensions obtained using the $\mu \mathrm{CT}$ v|tome| xs system from GE and GOM Inspect software form GOM GmbH.

For the next step of the research, two sets of parameters were chosen and applied to two selected specimens, No. 18 and 18a, which had the highest relative density, and No. 21 and 21a, which had the lowest dimensional difference between the CAD model and printed out specimens and the highest surface quality. Cuboids of given dimensions were used: for specimens 18 and $21-5 \times 0.2 \times 5 \mathrm{~mm}$, and for specimens $18 \mathrm{a}$ and $21 \mathrm{a}-5 \times 1 \times 5 \mathrm{~mm}$. Table 5 shows the values obtained at different laser treatment parameters and Figure 3 - the $\mu \mathrm{CT}$ image for specimen No. 21a.

Based on the results, the prosthetic elements (crowns and bridges) were made of the investigated $\mathrm{Ti}$ alloy at the parameters given above. The examples are shown in Figures $4-6$. The dimensional quality was very good for crowns, but the bridges were substantially deflected. The specific feature of the SLM method is that during printing of significant parts (of high dimensions) with complex geometry (curvatures), the large geometric deformations (dilatations, bending) may occur. Therefore, based on preliminary tests, some corrections of radiuses of arcs have been introduced to the stl. files in order to obtain the printed prosthetic bridges corresponding precisely to the CAD models.

\section{Discussion}

The research showed that for the Ti-13Zr-13Nb alloy the best results could be obtained by taking into account some specific material features of the Ti alloy as the low thermal conductivity and distinct differences between the melting temperature of three elements that make up this alloy, i.e., $\mathrm{Ti}, \mathrm{Zr}$, and $\mathrm{Nb}$.

As a rule, the highest densities of laser melted parts are obtained at the highest energy density. High energy density may be achieved at the highest laser power and scan rate values (one of the fundamental laser work parameters). This research did not confirm this supposition for the Ti alloy. The highest density $98.24 \%$ was found at the energy density $2 \mathrm{~J} / \mathrm{mm}^{2}$ while at the highest energy density $3.33 \mathrm{~J} / \mathrm{mm}^{2}$ the density was relatively low $-96.92 \%$. Presumably, at higher energy density the smaller powder grains (in a fraction comprising of grains of different size) may be evaporated in a shorter time resulting in a little smaller density of the melted layer. The better surface quality of the printed out specimens was also observed at lower energy density values. The best surface quality was achieved with laser treatment at laser power $80 \mathrm{~W}$, scan time $100 \mu \mathrm{s}$ and hatch distance $40 \mu \mathrm{m}$, with high dimensional quality and straightness of melting. The highest density and the best dimensional accordance of CAD and melted specimens (an accuracy between the target pattern and printed sample) can be obtained at laser power $100 \mathrm{~W}$, scan time $100 \mu$ s and hatch distance $50 \mu \mathrm{m}$.

The laser energy during the SLM process is used to heat the powder above melting temperature. Between laser energy application associated with heating and laser beam 


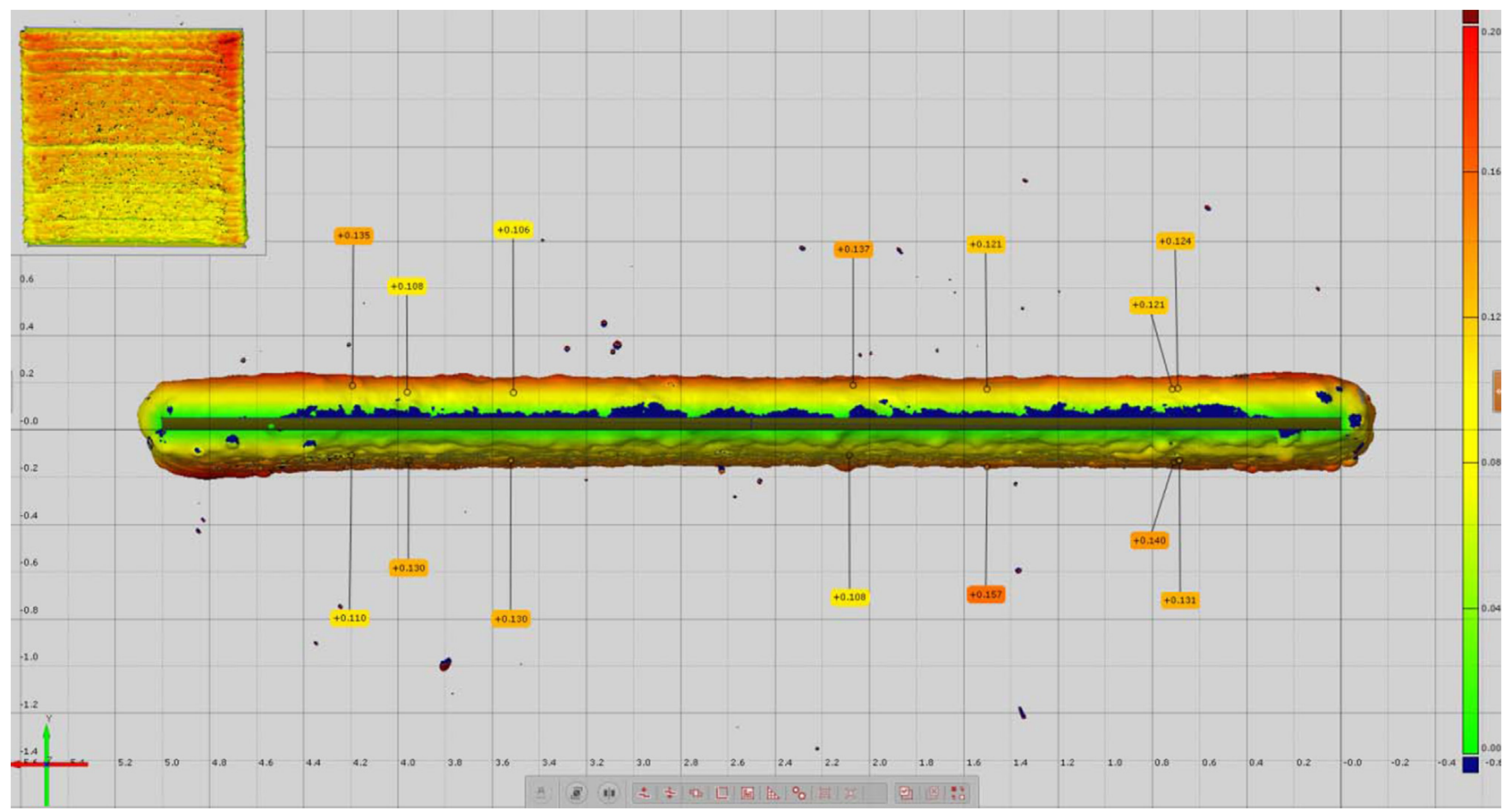

Fig. 1. Differences between the CAD model (dark yellow bar in the middle part of the sample) and printed out specimen No. 3 Top view.

Fig. 1. Comparaison entre le modèle CAO (barre jaune dans la partie centrale de l'échantillon) et le modèle produit $n^{\circ} 3$. Vue de dessus.

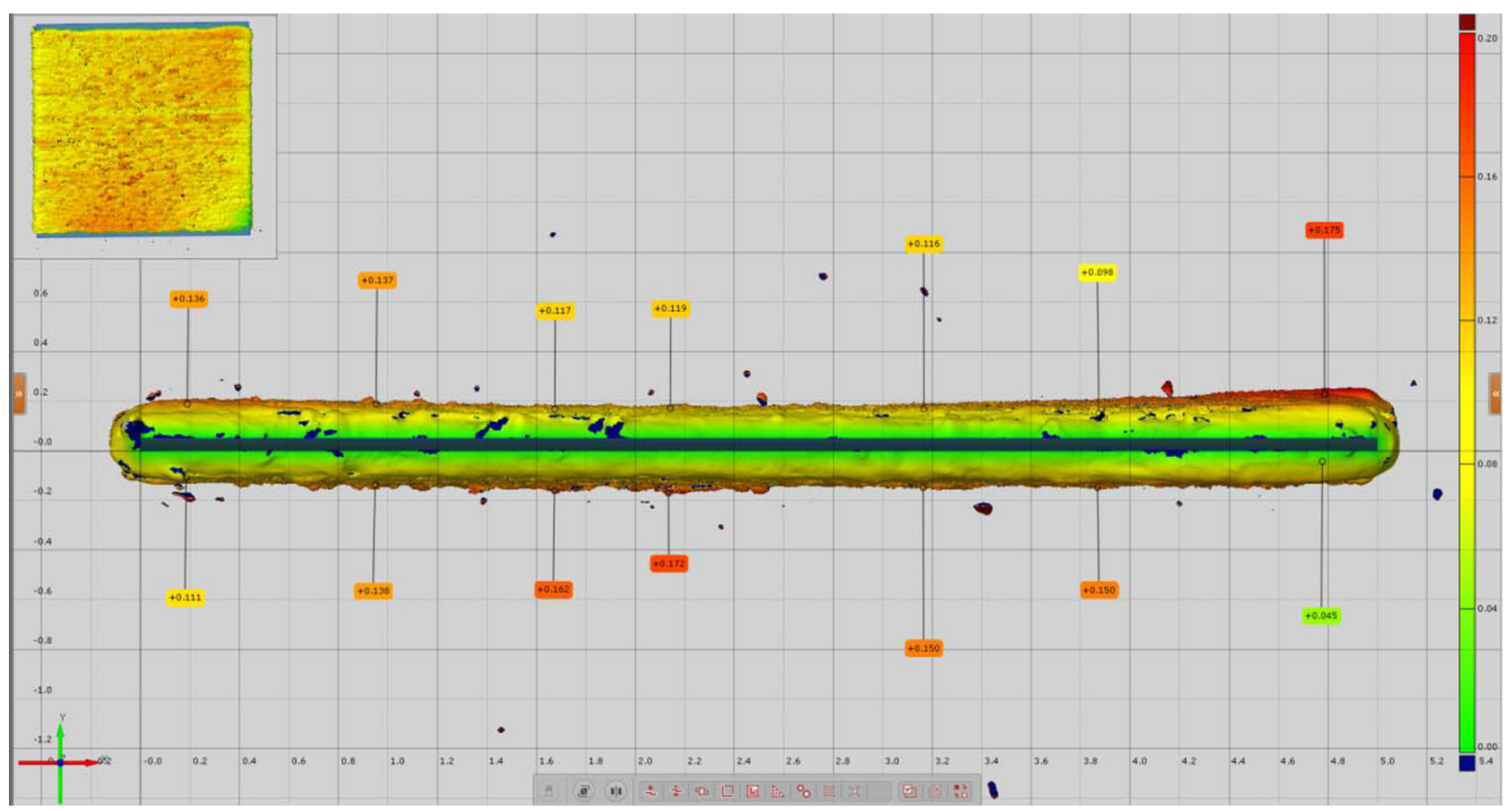

Fig. 2. Differences between the CAD model (navy blue bar in the middle part of the sample) and printed out specimen No. 21. Top view.

Fig. 2. Comparaison entre le modèle CAO (barre bleue dans la partie centrale de l'échantillon) et le spécimen imprimé $n^{\circ}$ 21. Vue de dessus. 
Table 5. Dimensions and density of the melted specimens No. 18, 18a, 21 and 21a.

Tableau 5. Dimensions et densité des éprouvettes $n^{\circ}$ 18, 18a, 21 et $21 a$.

\begin{tabular}{|c|c|c|c|c|c|c|c|}
\hline \multirow[b]{2}{*}{ No. } & \multicolumn{4}{|c|}{ Laser treatment parameters } & \multicolumn{2}{|c|}{ Dimensions $[\mathrm{mm}]$} & \multirow[b]{2}{*}{$\begin{array}{l}\text { Relative } \\
\text { density [\%] }\end{array}$} \\
\hline & $\begin{array}{l}\text { Laser } \\
\text { power [W] }\end{array}$ & $\begin{array}{l}\text { Scan } \\
\text { time }[\mu \mathrm{s}]\end{array}$ & $\begin{array}{l}\text { Hatch } \\
\text { distance }[\mu \mathrm{m}]\end{array}$ & Scan rate $[\mathrm{m} / \mathrm{s}]$ & $\begin{array}{l}\text { Width } \\
{[\mathrm{mm}]}\end{array}$ & $\begin{array}{l}\text { Thickness } \\
{[\mathrm{mm}]}\end{array}$ & \\
\hline 18 & 80 & 100 & 40 & 0.40 & 5.08 & 0.33 & 97.73 \\
\hline $18 \mathrm{a}$ & 80 & 100 & 40 & 0.40 & 5.14 & 1.11 & 98.86 \\
\hline 21 & 100 & 100 & 50 & 0.50 & 5.15 & 0.32 & 98.42 \\
\hline $21 \mathrm{a}$ & 100 & 100 & 50 & 0.50 & 5.42 & 1.10 & 98.81 \\
\hline
\end{tabular}

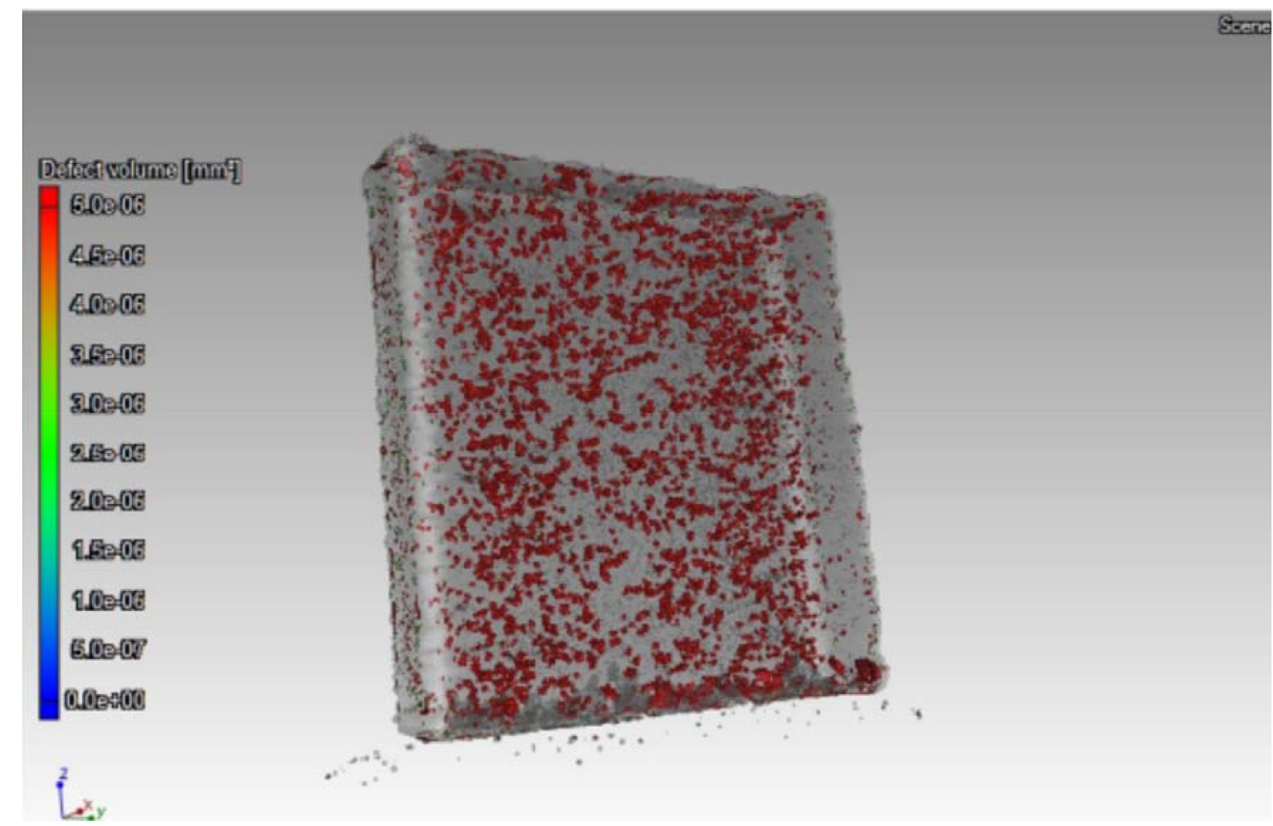

Fig. 3. 3D image of the intrinsic structure of specimen No. 21a, obtained by $\mu \mathrm{CT}$.

Fig. 3. Image 3D obtenue par $\mu C T$ de la structure intrinsèque de l'échantillon $n^{o} 21 a$.

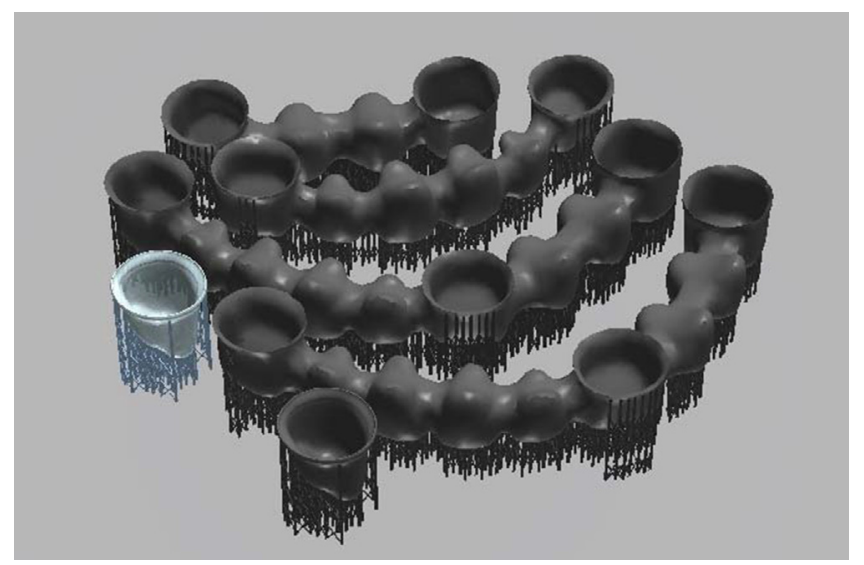

Fig. 4. View of the CAD model of the prosthetic crown with supports.

Fig. 4. Vue du modèle CAO de la couronne prothétique avec les supports. removal followed by cooling, different phenomena occur such as the transformation of solid particles of an alloy into liquid droplets, diffusion of the element in the formed liquid and crystallization of all elements. The power density (laser power on a unit area) and the exposure time in a single area (time means in which the scanning system focuses the laser beam at a single point) within the build layer (area) must be appropriately adjusted to melt the alloy; if one of these process parameters is too low, the melting cannot likely be completed, and the alloy structure after SLM would be inhomogeneous. The high temperature of the liquid causes a significant mixing of elements in a liquid state; the higher energy and exposure time, the better mixing. However, too high energy density and exposure time may result in excessive evaporation of lighter elements, the turbulent behavior of the liquid and an accumulation of thermal energy. During cooling period, the classical crystallization process occurs via formation of embryos and nuclei's and growth of crystals. If the cooling rate, determined by a 

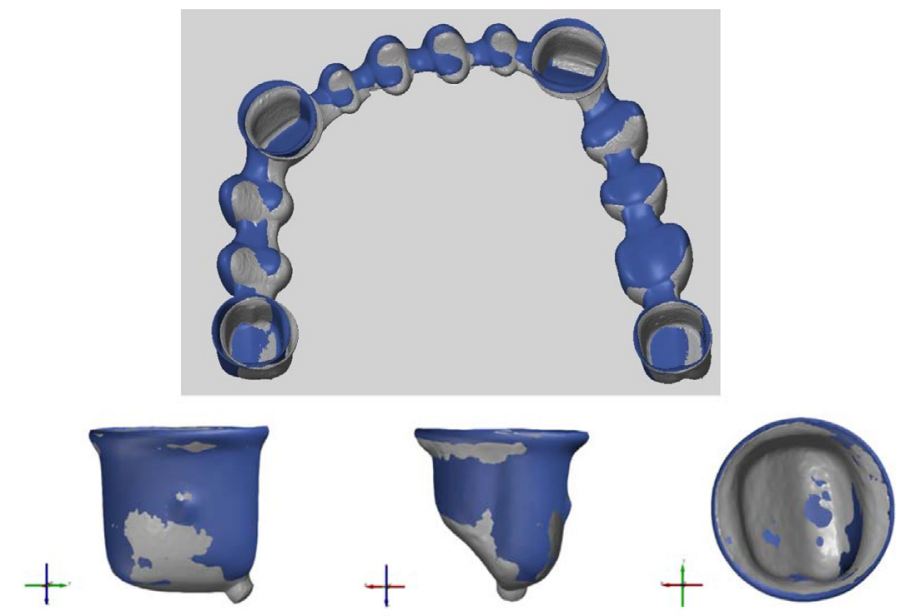

Fig. 5. Difference between the CAD model of the prosthetic elements (blue color) and the model obtained by $3 \mathrm{D}$ printing and reconstructed by $\mu \mathrm{CT}$ (grey color).

Fig. 5. Comparaison entre le modèle CAO des éléments prothétiques (couleurbleue) et du modèle obtenu, reconstruit par $\mu$ CT (couleur grise).

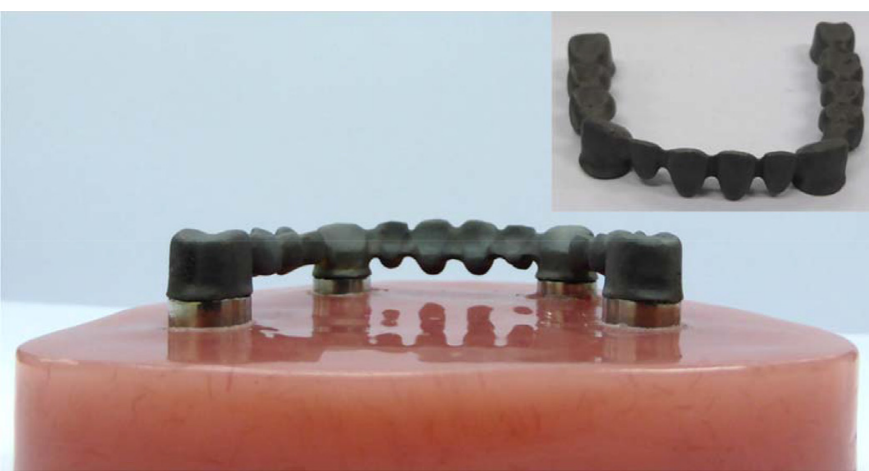

Fig. 6. View of high-quality prosthetic bridge obtained by SLM made of Ti-13Nb-13Zr alloy.

Fig. 6. Vue du pont prothétique de haute qualité obtenu par SLM en alliage $\mathrm{Ti}-13 \mathrm{Nb}-13 \mathrm{Zr}$.

difference between melted part temperature and titanium table temperature, and an environment thermal conductivity (here argon) is too low, the dendritic structure may be formed; if it is high, the desired amorphous, nanocrystalline and small grain structure appears, but simultaneously the cracks may occur. Different elements have different crystallization temperature, which additionally affects the appearing microstructure.

On the other hand, a perfect mixture of elements in a liquid state and fast cooling "frozen" distribution of atoms not allowing for significant diffusion in solid state and the alloy microstructure is far from equilibrium. In this research, no difference in the chemical composition has been noticed so that the diffusion in solid may be assumed as negligible. However, at such fast cooling, the martensitic transformation may take place. Taking into account all above considerations resulting from well-known models of laser melting [1, 28-29], the proper adjustment of these parameters may be said to be extremely important as it affects the homogeneity and surface quality, and the combination of the process parameters depends on the chemical and phase composition. Such an optimal combination was achieved in the present research. These differences are essential for the design of titanium parts and originate from the complex effects of energy density on melting rate and an approached temperature, and the difference between highest obtained temperature and that of the base plate influence the incubation and crystallization rates of the alloy components during the cooling period.

The importance of energy flux was observed in the last tests. Pre-heating the base plate to the proper temperature resulted in better heat dissipation. Energy density and energy flux may have a different influence on the quality of melted parts. When these values are too low, some powder grains may remain unmelted. When they are too high, high thermal stresses may be observed in printed-out objects, leading to greater dimension differences. Such a possibility must be taken into account at the design stage.

\section{Conclusions}

The energy density, scan rate, and energy flux are essential laser treatment parameters for sintering $\mathrm{Ti}-13 \mathrm{Zr}-13 \mathrm{Nb}$ alloy by the SLM/DMLS method. The best surface quality is achieved at a lower energy density, and the best density and dimensional accordance at a higher energy density.

The determination of process parameters for selective laser treatment of ternary $\mathrm{Ti}-13 \mathrm{Zr}-13 \mathrm{Nb}$ alloy is difficult because of the very different melting temperature of all alloying elements, low heat dissipation, and martensitic transformation $\beta-\alpha^{\star}$ during cooling. The different properties of alloying elements and their different contents cause that the optimal SLM parameters are to be determined individually for each Ti alloy.

Acknowledgments. The financial assistance, in the context of the TANGO1/266396/NCBR/2015 project, from the National Centre for Research and Development is gratefully acknowledged. The project is performed together with the Prosthetic Laboratory Jerzy Andryskowski, Gdansk. 


\section{References}

1. L.C. Zhang, H. Attar, Selective laser melting of titanium alloys and titanium matrix composites for biomedical applications: a review, Adv. Eng. Mater. 18, 463 (2016)

2. B. Vrancken, L. Thijs, J.P. Kruth, J. Van Humbeeck, Microstructure and mechanical properties of a novel $\beta$ titanium metallic composite by selective laser melting, Acta Mater. 68, 150 (2014)

3. Y.J. Liu, X.P. Li, L.C. Zhang, T.B. Sercombe, Processing and properties of topologically optimised biomedical Ti-24Nb4Zr-8Sn scaffolds manufactured by selective laser melting, Mater. Sci. Eng. A 642, 268 (2015)

4. E. Chlebus, B. Kuznicka, R. Dziedzic, T. Kurzynowski, Titanium alloyed with rhenium by selective laser melting, Mater. Sci. Eng. A 620, 155 (2015)

5. Y. Zhou, S.F. Wen, B. Song, X. Zhou, Q. Teng, Q.S. Wei, Y. S. Shei, A novel titanium alloy manufactured by selective laser melting: microstructure, high-temperature oxidation resistance, Mater. Des. 89, 1199 (2016)

6. M. Fischer, D. Joguet, G. Robin, L. Peltier, P. Laheurte, In situ elaboration of a binary $\mathrm{Ti}-26 \mathrm{Nb}$ alloy by selective laser melting of elemental titanium and niobium mixed powders, Mater. Sci. Eng. C 62, 852 (2016)

7. L. Yan, Y. Yuan, L. Ouyang, H. Li, A. Mirzasadeghi, L. Li, Improved mecha-nical properties of the new Ti-15Ta-xZr alloys fabricated by selective laser melting for biomedical application, J. Alloys Compd. 688, 156 (2016)

8. T. Ishimoto, K. Hagihara, K. Hisamoto, S.H. Sun, T. Nakano, Crystallographic texture control of beta-type Ti-15Mo-5Zr$3 \mathrm{Al}$ alloy by selective laser melting for the development of novel implants with a biocompatible low Young's modulus, Scr. Mater. 132, 34 (2017)

9. K. Wei, Z. Wang, X. Zeng, Preliminary investigation on selective laser melting of $\mathrm{Ti}-5 \mathrm{Al}-2.5 \mathrm{Sn} \mathrm{C}-\mathrm{Ti}$ alloy: From single tracks to bulk 3D components, J. Mater. Process. Technol. 244, 73 (2017)

10. W. Serbinski, A. Zielinski, T. Seramak, A. Ossowska, S. Sobieszczyk, M. Supernak, B. Majkowska, Surface treatment of porous Ti-13Nb-13Zr alloy for biomedical applications, Inzynieria Mater. 185, 6 (2012)

11. P.K. Maji, A.J. Banerjee, P.S. Banerjee. S. Karmakar, Additive manufacturing in prosthesis development - a case study, Rapid Prototyp. J. 20, 480 (2014)

12. D. Joguet, S. Costil, H. Liao, Y. Danlos, Porosity content control of CoCrMo and titanium parts by Taguchi method applied to selective laser melting process parameter, Rapid Prototyp. J. 22, 20 (2016)

13. L.Y. Chen, J.C. Huang, C.H. Lin, et al., Anisotropic response of Ti-6Al-4V alloy fabricated by $3 \mathrm{D}$ printing selective laser melting, Mater. Sci. Eng. A 682, 389 (2017)

14. A.R. Lapcevic, D.P. Jevremovic, T.M. Puskar, et al., Comparative analysis of structure and hardness of cast and direct metal laser sintering produced Co-Cr alloys used for dental devices, Rapid Prototyp. J. 22, 144 (2016)

15. M. Fantini, F. De Crescenzio, L. Ciocca, F. Persiani, Additive manufacturing to assist prosthetically guided bone regeneration of atrophic maxillary arches, Rapid Prototyp. J. 24, 705 (2015)

16. P.J.T. Conradie, D. Dimitrov, G.A. Oosthuizen, et al., Comparative assessment of process combination for Ti6Al4V components, Rapid Prototyp. J. 23, 624 (2017)

17. H. Hassanin, et al., Net-shape manufacturing using hybrid selective laser melting/hot isostatic pressing, Rapid Prototyp. J. 23, 720 (2017)

18. Q. Zhang, et al., Microstructure and mechanical properties of Ti6Al4V alloy prepared by selective laser melting combined with precision forging, Trans. Nonferrous Met. Soc. China 27, 1036 (2017)

19. A.M. Khorasani, I. Gibson. M. Goldberg, G. Littlefair, On the role of different annealing heat treatments on mechanical properties and microstructure of selective laser melted and conventional wrought Ti-6Al-4V, Rapid Prototyp. J. 23, 295 (2017)

20. E. Santos, et al., Fabrication of titanium dental implants by selective laser melting, Proc. SPIE 5662, 5th Intl. Symp. Laser Precision Microfabr., 2004.

21. B. Gao, J. Wu, X. Zhao, H. Tan, Fabricating titanium denture base plate by laser rapid forming, Rapid Prototyp. J. 15, 133 (2009)

22. Y. Yang, J.-B. Lu, Z.-Y. Luo, D. Wang, Accuracy and density optimization in directly fabricating customized orthodontic production by selective laser melting, Rapid Prototyp. J. 18, $482(2012)$

23. M. Kanazawa, M. Iwaki, S. Minakuchi, N. Nomura, Fabrication of titanium alloy frameworks for complete dentures by selective laser melting, J. Prosthet. Dentistry 112, 1441 (2014)

24. N.K. Tolochko, et al., Mechanisms of selective laser sintering and heat transfer in Ti powder, Rapid Prototyp. J. 9, 314 (2003)

25. B. Vandenbroucke, J.-P. Kruth, Selective laser melting of biocompatible metals for rapid manufacturing of medical parts, Rapid Prototyp. J. 13, 196 (2007)

26. T. Marcu, et al., Selective laser melting of Ti6Al7Nb with hydroxyapatite addition, Rapid Prototyp. J. 20, 301 (2014)

27. X.P. Li, J. Van Humbeeck, J.P. Kruth, Selective laser melting of weak-textured commercially pure titanium with high strength and ductility: A study from laser power perspective, Mater. Des. 116, 352 (2017)

28. S. Bremen, W. Meiner, A. Diatlow, Selective laser melting. A manufacturing technology for the future? Laser Technik J. 2 $33(2012)$

29. E. Chlebus, B. Kuznicka, R. Dziedzic, T. Kurzynowski, Titanium alloyed with rhenium by selective laser melting, Mater. Sci. Eng. A 620, 155 (2015)

Cite this article as: Tomasz Seramak, Katarzyna Zasinska, Michel Mesnard, Karolina Bednarz, Paulina Fic, Andrzej Zielinski, Determinants of the surface quality, density and dimensional correctness in selective laser melting of the Ti-13Zr-13Nb alloy, Matériaux \& Techniques 106, 405 (2018) 